\title{
The use of prone positioning in severe COVID-19 outside the intensive care unit
}

\author{
Yildiz $\mathrm{M}^{1}$, Ozturk Ergur $\mathrm{F}^{1}$, Uzel Senel $\mathrm{M}^{2}$, Kavurgaci $\mathrm{S}^{1}$, Ozturk $\mathrm{A}^{2}$ \\ Health Sciences University Faculty of Medicine, Ankara Ataturk Chest Disease and Chest Surgery Training and Research Hospital, \\ Interventional Pulmonology Department, Kuscagiz-Kecioren, Ankara, Turkey.drayperi@yahoo.com
}

\begin{abstract}
OBJECTIVES: It was aimed to demonstrate the applicability of the prone position with high-flow oxygen to COVID-19 patients with severe respiratory failure in the service in September when the number of cases and the need for intensive care were increased.

MATERIAL AND METHODS: The prone position was applied for a minimum of 30-minute periods for at least four hours a day. The patients' oxygen saturation levels and respiration rates were monitored before and 30 minutes after prone positioning.

RESULTS: Ten patients, nine males (9/1, M/F), were included in the study. Mean oxygen saturation at baseline was $75.8 \pm 12.14$ ( $\mathrm{min}: 50 \%$; max: $90 \%$ ) and all patients had high oxygen demand. The oxygen saturation of the patients differed significantly before and after $(83.4 \pm 6.38 \% ; 90 \pm 5.31 \%, p<0.001)$ prone positioning. Similarly, respiration rates differed significantly before and after $(23.9 \pm 6 ; 21.4 \pm 4.97, p<0.001)$ prone positioning. Two patients died during treatment.

CONCLUSION: This study highlights the promise of prone positioning performed in ward conditions for improving oxygenation in COVID-19. While the study contains a small group, it may provide guidance for the clinical management of COVID-19 patients to prevent the need for intensive care in the challenging course of therapy (Tab. 2, Fig. 2, Ref. 15). Text in PDF www.elis.sk KEY WORDS: COVID-19, prone position, oxygen, saturation.
\end{abstract}

\begin{abstract}
Abbreviations: ARDS - acute respiratory disstres sydrome, BMI - body mass index, COVID-19 - Corona Virus Disease-19, $\mathrm{CRP}$ - C-reactive protein, $\mathrm{FiO}_{2}$ - fraction of inspired oxygen, HFNO - high-flow oxygen treatment, ICUs - Intensive care units, $\mathrm{PA}$ - posteroanterior, $\mathrm{PaO}_{2}$ - partial arterial oxygen pressure, PPL - pleural pressure, PTP - transpulmonary pressure, RTPCR - real-time reverse transcriptase-polymerase chain reaction, SARS-CoV-2 - severe acute respiratory syndrome corona virus 2, $\mathrm{SpO}_{2}$ - oxygen saturation, SPSS - Statistical Package for Social Sciences, SSC - surviving sepsis campaign.
\end{abstract}

\section{Introduction}

Corona virus disease-19 (COVID-19), a respiratory disease caused by severe acute respiratory syndrome coronavirus 2 (SARSCoV-2) that has spread globally, is highly contagious and associated with high mortality (1). A simple, effective treatment for

${ }^{1}$ Health Sciences University Faculty of Medicine Atatürk Chest Diseases and Thoracic Surgery Training and Research Hospital, Pulmonary Medicine Department, Ankara, Turkey, and ${ }^{2}$ Health Sciences University Faculty of Medicine Atatürk Chest Diseases and Thoracic Surgery Training and Research Hospital, Interventional Pulmonology Department, Ankara, Turkey

Address for correspondence: A. Ozturk, Ass Prof, Health Sciences University Faculty of Medicine, Ankara Ataturk Chest Disease and Chest Surgery Training and Research Hospital, Interventional Pulmonology Department, 06280, Kuscagiz-Kecioren, Ankara, Turkey.
COVID-19 is urgently needed to reduce admissions to intensive care units (2). When patients are in a supine position, dorsalventral transpulmonary pressure can cause impaired oxygenation due to ventral alveolar inflation and dorsal alveolar atelectasis (3, 4). Prone positioning reduces this pressure difference, resulting in ventral homogeneity and thereby increasing ventral alveolar inflation and reducing dorsal alveolar atelectasis. This can then reduce the risk of hypoxia as the ventilation/perfusion ratio is improved by the redistribution of blood from non-ventilated regions to ventilated ones (5). End-expiratory lung volume is also greater in a prone position (6). Previous studies have consistently shown that, in most patients with acute respiratory distres sydrome (ARDS) (up to $70 \%$ ), prone ventilation increases partial arterial oxygen Pressure $\left(\mathrm{PaO}_{2}\right)$, reducing patients' fraction of inspired oxygen $\left(\mathrm{FiO}_{2}\right)$ requirements $(7,8)$.

This study aimed to examine the applicability and efficiency of prone positioning outside the ICU in order to determine its relevance as a convenient, simple, effective method for reducing mortality in COVID-19 patients with severe hypoxia.

\section{Materials and methods}

\section{Patient selection}

This study was conducted at the Ankara Atatürk Chest Diseases and Chest Surgery Training and Research Hospital. The study included patients admitted to hospital with confirmed COVID-19 
Tab. 1. Demographic features of patients.

\begin{tabular}{|c|c|}
\hline & Prone positioned patients $(\mathrm{n}=10)$ \\
\hline Age (years) & $52.3 \pm 11.3(39-66)$ \\
\hline \multicolumn{2}{|l|}{ Gender } \\
\hline Male & $9(90 \%)$ \\
\hline Female & $1(10 \%)$ \\
\hline BMI (kg/m2) & $29.84 \pm 4.32$ \\
\hline \multicolumn{2}{|l|}{ Comorbidities } \\
\hline Hypertension & $1(10 \%)$ \\
\hline DM & $3(30 \%)$ \\
\hline CAD & $2(20 \%)$ \\
\hline Asthma & $1(10 \%)$ \\
\hline Familial Mediterranean Fever & $1(10 \%)$ \\
\hline Mean length of stay (days) & 10.6 \\
\hline \multicolumn{2}{|l|}{ Baseline values: } \\
\hline WBC & $6295.56 \pm 2249.58$ \\
\hline Neutrophil count & $5026.67 \pm 2482.9$ \\
\hline Lymphocyte count & $915.56 \pm 429.42$ \\
\hline Neutrophil/lymphocyte ratio & $4.72(2.63-34.7)$ \\
\hline Hemoglobin & $13.93 \pm 1.04$ \\
\hline Platelet count & $213444.4 \pm 28076.28$ \\
\hline AST & $61(30-161)$ \\
\hline ALT & $38(14-258)$ \\
\hline CRP & $90(3,1-189)$ \\
\hline D-dimer & $607.78 \pm 310.5$ \\
\hline Ferritin & $654(97-1650)$ \\
\hline Troponin & $7.5(0-45)$ \\
\hline Creatinine & $1.02 \pm 0.2$ \\
\hline Saturation & $75.8 \pm 12.14(50-90)$ \\
\hline $\mathrm{FiO} 2$ & $57.5(45-100)$ \\
\hline Fever $\left(>38^{\circ}\right)$ & $2(20 \%)$ \\
\hline Number of involved lobes on CT & $4.78 \pm 0.67$ \\
\hline Plaqueniltreatment & $8(80 \%)$ \\
\hline Faviripavirtreatment & $10(100 \%)$ \\
\hline Favipiravirtreatment duration & $8.7 \pm 2.83$ \\
\hline Steroids & $10(100 \%)$ \\
\hline \multicolumn{2}{|l|}{$\begin{array}{l}\text { Enoxaparine treatment } \\
\text {. }\end{array}$} \\
\hline Prophylactic (dosage:0.4,SID) & $7(70 \%)$ \\
\hline Therapeutic (dosage: 0.6 BID) & $3(30 \%)$ \\
\hline Antibiotic treatment & $10(100 \%)$ \\
\hline Vitamin C treatment & $9(90 \%)$ \\
\hline \multicolumn{2}{|l|}{ Baseline $\mathrm{O} 2$ treatment } \\
\hline Nasal & 7 (70\%) \\
\hline Venturi & $1(10 \%)$ \\
\hline High-flow & $2(20 \%)$ \\
\hline Exitus & $2(20 \%)$ \\
\hline
\end{tabular}

between 1st September 2020 and 1st October 2020. Cases of COVID-19 were diagnosed using real-time reverse transcriptasepolymerase chain reaction tests. The inclusion criteria were as follows: First, included patients were over 18 years of age and tested positive for COVID-19 on a RT-PCR test. Included patients also experienced hypoxic respiratory failure, were conscious, and did not require intubation. They could tolerate a prone position for at least 30 minutes and had undergone thoracic tomography and/or posteroanterior chest x-rays. Finally, other data necessary for the study were available for all included patients. Patients; - under 18 years of age, - unconscious patients, - patients followed up with only nasal oxygen, - those with hypoxic respiratory failure who required intubation, - patients with obesity or anatomic deformities that restricted positioning, and - patients for whom the data on file were incomplete were excluded from the study.

\section{Prone positioning}

The patients were informed about the prone position and placed in a prone position for at least four hours per day. This treatment was combined with nasal O2, venturi mask or high-flow oxygen treatment. The patients' oxygen saturation levels and respiration rates were monitored before and 30 minutes after prone positioning. The differences between pre- and post-prone positioning oxygen saturation levels and respiration rates were evaluated.

\section{Statistical methods}

The data were analysed using SPSS 21.0 (Statistical Package for Social Sciences for Windows, Inc., Chicago, Illinois, USA). The distribution of data normality was determined using the Kolmogorov-Smirnov test. The data were reported as mean \pm standard deviation for normally distributed continuous variables, as median (minimum-maximum) for non-normally distributed continuous variables and as $\mathrm{n}(\%)$ for categorical variables. The values before and after prone positioning were compared using the paired samples t-test. Statistical significance was set at $\mathrm{p}<0.05$.

\section{Results}

360 patients were hospitalized and followed up in the clinic between 1st September and 1st October. Oxygen therapy was served to 319 patients by nasal cannula (2-4lt / min), 19 patients by a venturi mask, 19 patients by high flow nasal cannula, and 1 patient with NIMV. 2-4 lt / min oxygen therapy given by nasal cannula was considered to be mild to moderate hypoxia, and was excluded from the study. When the remaining 41 patients were evaluated with the inclusion criteria; patients with unconsciousness (3), obesity(18), kyphoscoliosis (5), unable to adapt to prone position (5) were excluded. The remaining ten patients were included in the study and analyzed.

Of ten patients nine (90\%) were males and one was (10 \%) female. All the patients had a mean body mass index of $29.84 \pm$ 4.32. Patients' demographics are summarized in Table 1 . Steroids and favipiravir were used in treatment of all patients. Nine were given vitamin $\mathrm{C}$, and eight were given concomitant hydroxychloroquine. At baseline, the patients had low mean lymphocyte counts, however neutrophil-lymphocyte ratios, C-reactive protein, D-dimer, and ferritin values were high (Tab. 1). Mean oxygen saturation $\left(\mathrm{SpO}_{2}\right)$ at baseline was $75.8 \pm 12.14$ (min: $50 \%$; max: $90 \%$ ) and all patients had high oxygen demand (nasal $\mathrm{O}_{2}: \mathrm{n}=7$; venturi mask: $\mathrm{n}=1$; HFNO: $\mathrm{n}=2$ ). $\mathrm{Mean}_{\mathrm{FiO}}$ was $57.5 \%$ (min:

Tab. 2. Differences between pre and post prone positioning.

\begin{tabular}{lccc}
\hline & $\begin{array}{c}\text { Pre Prone } \\
\text { Positioning }\end{array}$ & $\begin{array}{c}\text { Post Prone } \\
\text { Positioning }\end{array}$ & $\mathrm{p}$ \\
\hline Respiration rate & $23.9 \pm 6$ & $21.4 \pm 4.97$ & $<0.001$ \\
Saturation (\%) & $83.4 \pm 6.38$ & $90 \pm 5.31$ & $<0.001$ \\
\hline
\end{tabular}




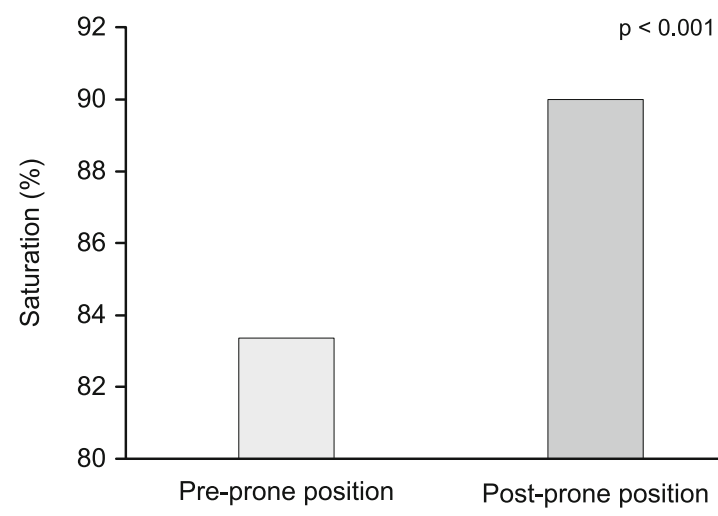

Fig. 1. The oxygen saturation of the patients differed significantly before $(83.4 \pm 6.38 \%)$ and after $(90 \pm 5.31 \%)$ prone positioning $(\mathrm{p}<0.001)$.

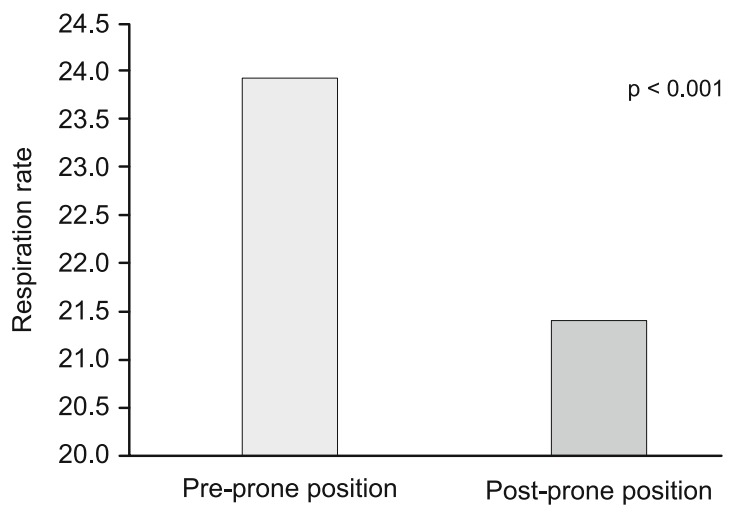

Fig. 2. Respiration rates varied significantly before $(23.9 \pm 6)$ and after $(21.4 \pm 4.97)$ prone positioning $(p<0.001)$.

$45 \%$; max: $100 \%)$. Bilateral multilobar ground-glass opacity and consolidation that indicated severe pneumonia, were present on the computerized tomography in all patients. The oxygen saturation of the patients differed significantly before (83.4 $\pm 6.38 \%)$ and after $(90 \pm 5.31 \%)$ prone positioning ( $<0.001)$ (Tab. 2, Fig. 1). Similarly, respiration rates varied significantly before $(23.9 \pm 6)$ and after $(21.4 \pm 4.97)$ prone positioning $(\mathrm{p}<0.001)$ (Fig. 2). Two patients $(20 \%)$ died during treatment.

\section{Discussion}

In this study, the applicability of prone positioning performed in ward conditions for improving oxygenation in a challenging course of COVID-19 was highlighted. While the study contains a small group, it may provide guidance for the clinical management of COVID-19 patients to prevent the need for intensive care in the challenging course of therapy.

Hypoxia is the most common problem in patients with severe COVID-19, and approximately $40 \%$ of these patients develop ARDS (9). Recent studies have shown that prone positioning can be used to treat hypoxemic acute respiratory failure in non-intubated, awake COVID-19 patients (2). When the patient lies in a supine position, the dorsal pleural pressure (PPL) is greater than the ventral PPL; thus, the ventral transpulmonary pressure (PTP) exceeds the dorsal PTP, causing the ventral alveoli to inflate more than the dorsal alveoli. This effect is exaggerated in patients with ARDS since the difference between dorsal and ventral pleural pressures is increased as a result of excessive lung weight, leading to excessive inflation of the ventral alveoli and atelectasis of the dorsal alveoli $(3,4)$. Prone positioning reduces the difference between dorsal and ventral PTP values, producing homogeneous pressure in the ventral areas (5), increasing ventral alveolar inflation and reducing dorsal alveolar collapse (10). An alternative mechanism is the increased end-expiratory lung volume that occurs when a patient lies in a prone position (6).

Conventional invasive mechanical ventilation is administered with the patient in supine position. Prone ventilation is a strategy used to improve oxygenation in ARDS patients when conventional ventilation modes (e.g. lung protective ventilation) are unsuccessful. Studies have shown that prone positioning may correct oxygenation in non-intubated, awake patients better than in intubated patients; this treatment can avoid the need for intubation as well as the complications associated with intubation and mechanical ventilation (11).

Studies have consistently shown that, in most patients with ARDS (up to $70 \%$ ), prone ventilation increases $\mathrm{PaO} 2$, reducing the patient's $\mathrm{FiO}_{2}$ requirements $(7,8)$. Zang et al placed 23 ICU patients with severe hypoxia in an early prone position (12). In this study, patients' oxygen saturation increased from $91.09 \pm 1.54 \%$ to $95.30 \pm 1.72 \%$ after ten minutes $(\mathrm{p}<0.01)$ and to $95.48 \pm 1.73 \%$ after 30 minutes $(\mathrm{p}<0.01)$ and the differences between ten and 30 minutes were not significant $(\mathrm{p}=0.58)$. Furthermore, patients' respiration rates reduced from $28.2 \pm 3.06$ breaths/min to $27.78 \pm 2.75$ breaths/min after ten minutes ( $\mathrm{p}=0.20)$ and to $24.87 \pm 1.84$ breaths/ $/$ min after 30 minutes $(\mathrm{p}<0.01)$ and there was no significant difference in respiration rate at ten minutes compared to the baseline $(p=0.203)(12,13)$. In another study, Moghadam et al randomly selected ten non-ICU non-intubated COVID-19 patients (70 \% male, $30 \%$ female) with a mean age of 41 years for treatment with prone positioning. Participants in that study had a mean SpO2 before and after prone positioning of $85.6 \%$ and $95.9 \%$, respectively. All of the patients were discharged after a mean of 4.8 days of hospitalization (13). Similarly, in the current study, ten patients (mean age 52 years) with severe hypoxia were treated in ward conditions with a minimum of four hours of prone positioning per day. A remarkable improvement in both the patients' oxygen saturation levels and respiration rates was identified after 30 minutes of prone positioning.

Zang et al conducted follow-up evaluations 90 days after treatment. Ten (43.5\%) of the 23 COVID-19 patients in the prone position group died within 90 days (12). In our study, the mean duration of hospitalization for the patients was 10.6 days and eight (80 \%) patients were discharged, while two (20\%) died.

Although the beneficial effects of prone positioning on hypoxemia in COVID-19 patients in ICUs were emphasized in the reviews and guidelines $(14,15)$ only a few studies were present 
about the use of prone positioning in outside ICU. Whereas it may bet also applied successfully in the clinic by a close follow-up.

The study had several limitations. First, it was a retrospective study; second, the sample was too small, and lastly, arterial blood gases were not analyzed.

\section{Conclusion}

The prone positioning is an effective, simple, easy, sustainable, repeatable therapy for inpatient (outside ICU) in the supportive treatment of severe COVID-19 pneumonia. We predict that with the widespread use of this form of treatment, the transfer to the ICU will decrease, hence ICU overload will reduce. At the same time, it can be thought that intubation will abate, so complications and mortality associated with intubation will decrease.

\section{References}

1. Huang C, Wang Y, Li W et al. Clinical Features of Patients Infected With 2019 Novel Coronavirus in Wuhan, China Lancet 2020; 395 (10223): 497-506. DOI: 10.1016/S0140-6736(20)30183-5.

2. Elharrar X, Trigui Y, Dols A et al. Use of Prone Positioning in Nonintubated Patients With COVID-19 and Hypoxemic Acute Respiratory Failure. JAMA 2020; 323 (22): 2336-2338. DOI: 10.1001/jama.2020.8255.

3. Pelosi P, Brazzi L, Gattinoni L. Prone position in acute respiratory distress syndrome. Eur Respir J 2002; 20: 1017.

4. Gattinoni L, Mascheroni D, Torresin A et al. Morphological response to positive end expiratory pressure in acute respiratory failure. Computerized tomography study. Intensive Care Med 1986; 12: 137.

5. Lai-Fook SJ, Rodarte JR. Pleural pressure distribution and its relationship to lung volume and interstitial pressure. J Appl Physiol 1985; 70: 967.
6. Douglas WW, Rehder K, Beynen FM, Sessler AD, Marsh HM. Improved oxygenation in patients with acute respiratory failure: The prone position. Am Rev Respir Dis 1977; 115: 559-566

7. Pelosi P, Tubiolo D, Mascheroni D et al. Effects of the prone position on respiratory mechanics and gas exchange during acute lung injury. Am J Respir Crit Care Med 1998; 157: 387.

8. Mure M, Martling CR, Lindahl SG. Dramatic effect on oxygenation in patients with severe acute lung insufficiency treated in the prone position. Crit Care Med 1997; 25: 1539.

9. Wu C, Chen X, Cai Y et al. Risk Factors Associated with Acute Respiratory Distress Syndrome and Death in Patients with Coronavirus Disease 2019 Pneumonia in Wuhan, China. JAMA Intern Med 2020; 180 (7): 934-943. DOI: 10.1001/ jamainternmed 2020.0994.

10. Cornejo RA, Díaz JC, Tobar EA et al. Effects of prone positioning on lungprotection in patients with acute respiratory distress syndrome. Am J Respir Crit Care Med 2013; 188: 440.

11. Valter C, Christensen AM, Tollund C, Schonemann NK. Response to the prone position in spontaneously breathing patients with hypoxemic respiratory failure. Acta Anaesthesiol Scand 2003; 47: 416-418.

12. Zang X, Wang Q, Zhou H, Liu S, Xue X. COVID-19 Early Prone Position Study Group. Efficacy of early prone position for COVID-19 patients with severe hypoxia: a single-center prospective cohort study. Intensive Care Med 2020; 46(10): 1927-1929. DOI: 10.1007/s00134-020-06182-4.

13. Moghadam VD, Shafiee H, Ghorbani M, Heidarifar R. Prone positioning in management of COVID-19 hospitalized patients. Braz J Anesthesiol 2020; 70(2): 188-190.

14. Kazim Rollas, Nimet Şenoglu. Management of Covid-19 Patients In Intensive Care Unit. J Tepecik Educ Res Hosp 2020; 30(2): 142-155.

15. Alhazzani W, Moller M, Arabi Y et al. Surviving Sepsis Campaign: Guidelines on the Management of Critically Ill Adults with Coronavirus Disease 2019 (COVID-19) Intensive Care Med 2020; 46(5): 854-887.

Received February 9, 2021. Accepted March 3, 2021. 